\title{
DETERMINATION OF THE STRENGTH PERFORMANCE OF TABLE FRAMES
}

\author{
Igor Džinčićc ${ }^{1, \star}$ \\ Tanja Palija ${ }^{1}$ \\ Dragan Živanićc \\ Vojislav Dacić3
}

\begin{abstract}
The objective of this study was to investigate the relation of diameter of pilot hole and screw, and machining accuracy on withdrawal strengths of the screws and durability of the dining tables. For this purpose, fasteners and material types on the failure loads of dining table corner joints have been analyzed experimentally and statistically. Double ended thread bolts with different drilling regimes have been used as fastener types. A parallel investigation of rigidity and durability of tables, and withdrawal capacities in accordance with the according to current norms, was performed. According to the results, it is concluded that the diameter of the drilled hole significantly influences the value of the withdrawal strengths of the screws. By analyzing the effect of drilling diameter on the rigidity of tables, a statistically significant difference was determined. As the drilling diameter increases, the rigidity of the examined dining tables decreases.
\end{abstract}

Keywords: Durability, joints, screws, tables, withdrawal strengths.

\section{INTRODUCTION}

Determing the quality of dining tables according to the EN norms, shows that horizontal fatigue is one of the most important factors of durability. Based on the insight into testing results of the Institute for Control of Furniture Quality of the Faculty of Forestry-University of Belgrade, Serbia, (over 1000 samples), it can be said that the stength and durability are in the function of the quality of the dining tables. When we are analyzing the quality of the dining tables, we have to make a difference between tables with no extension (hereinafter referred as fix tables) and tables with the possibility of extension (hereinafter referred as XL tables). The stength and durability of fixed tables are influenced by the following factors: table size, conecting solution between rails and table top, and the way of connecting legs to the underconstruction. The stength and durability of the $\mathrm{XL}$ tables will depend on the type of slider, the way how it is attached to the underconstruction, the length of the draw, the size of the ovelap over the slider, and the number of metal ball-retainers in the slider. According to the testing results of the Institute for Control of Furniture Quality, XL tables have two critical points in the construction which colud the cause for the potential appearance of consumer complaints: the rigidity of the system and the deflection of the table top when the table is open. On the other hand, fixed tables has no problem with table top deflection. If the main board is connected to the understructure in the propprer way, the source of the problem can only be a connection of the leg and rails. In this case, the stength and durability of the table will be influenced by the choice of corner brackets, as well as factors that affect the withdrawal strengths of the screws (type of wood, wood moisture, the anatomical direction in which the screw is placed, the type and

\footnotetext{
${ }^{1}$ Belgrade University, Faculty of Forestry, Belgrade, Republic of Serbia.

${ }^{2}$ University of Novi Sad, Faculty of Technical Sciences, Novi Sad, Republic of Serbia.

${ }^{3}$ Company Union Drvo, Belgrade, Republic of Serbia.

•Corresponding author: Igor.dzincic@sfb.bg.ac.rs

Received: 31.12.2020 Accepted: 04.06.2021
} 
dimensions of the hole (diameter, length) in which the screw is placed, as well as the depth of hole at which the screw is placed.

Since fixed tables are mostly located in the lowest price classes (ex-work price; source: table manufacturers that are export-oriented), and can not stand a high percentage of consumer complaints, putting under the control factors which effects its quality is crucial. The aim of the paper is to examine the impact of withdrawal strengths of the screws on the strength and durability of fixed dining tables.

As stated numerous times before, the strength of the wooden furniture manly depends on the strength of the joints and they represent critical points in the construction Skakić and Janićijević (2000), Smardzewski and Papuga (2004), Gavronski (2006), Atar and Ayhan (2008), Abdulkadir et al. (2014), Yuksel et al. (2014), Yuksel et al. (2015), Chen and Lyu (2018). Most of the researchers analyzed certain factors that affects the withdrawal strengths of the screws, since the connection with the screw is widely applied in furniture production: Eckelman (1975), Taj et al. (2009), Akyildiz and Malkoçoglu (2001), Gašparik et al. (2015), Tankut (2011), Dacić et al. (2017a). Broker and Krause (1991) investigated both static and dynamic screw withdrawal strengths on three different types of materiaals (particleboard, European Spruce and Birch) wood with 9 types of screws. They concluded that the screw withdrawal resistance value is linearly proportional with screw length and screw diameter. Kjucukov and Encev (1977a) investigated screw withdrawal strengths from Abies alba wood in three directions varying screws lengths $(13 \mathrm{~mm} \div 60 \mathrm{~mm})$ and diameters $(1,5 \mathrm{~mm} \div 8$ $\mathrm{mm})$. After extensive examination they concluded that there is a linear relationship between screw withdrawal resistance and screw diameter. In their fallowing paper Kjucukov and Encev (1977b) repeated tests with screw variation from $1,5 \mathrm{~mm}$ to $6,0 \mathrm{~mm}$ on Fagus orientalis and determined that there is a linear relationship between screw withdrawal resistance and screw diameter. Akyildiz and Malkocoglu (2001), conduct their experiment on five diferent wood species at two moisture contents (12\% and $30 \%)$. Screws used for withdrawal capacities tests were $4,5 \mathrm{~mm}$ x $40 \mathrm{~mm}$ with a lead holes of $26 \mathrm{~mm}$. According to obtained results, they concluded that beech wood had highest values of screw withdrawal resistance among five tree species, and that mositure content effects withdrawal resistance.

Yorur et al. (2020) analyse direct screw withdrawal force from various types od wood based panels. Among other things, they concluded that existance of pilot hole has significant influence on withdrawal strength. Screws with predrilled holes was combined with two types of adhesives.

On the basis of above mentioned results new experiment was set pointing in two directions: testing withdrawal strengths of the screws varying relation of diametar of pilot hole and screw, and machinning accuracu, and testing durability and rigidity of dining tables constructed with different drilling regimes. Results obtaind upon conducted experiment should give answer the following question: Is it possible to predict strength and durability of the dining tables on the basis of the value of the withdrawal strengths of the screws?

\section{MATERIAL AND METHODS}

Considering that the influence of wood species, moisture of wood and anatomical direction on the withdrawal strengths of the screws, was the subject of an analysis by other authors, in this paper two other analyzes will be performed: Examination of the impact of the diameter of hole and machinning accuracy of drilling on the strength of the joint with the screw, and Testing the strength and durability of dining tables.

\section{Withdrawal capacities of the screws}

Analyzing the EU market in the last five years, it can be concluded that the dining tables are mostly made of solid wood of beech and oak, while the joints of the legs with the rails are made with metal or wooden corner brackets, using double ended thread bolt (Figure 1). Since beech is the most important industrial species in the south-eastern part of Europe, the samples will be made of this type of wood. The double ended thread bolts allowes knock-down construction (flat pack), and give the appropriate strength and rigidity of the construction. Based on the review of the technical documentation of the Institute for Control of Furniture Quality of the Faculty of Forestry in the last five years, it can be concluded that there is no definition among furniture manufacturer according to a certain type of those screws. Choice is most often driven by the movement of prices on the market. 
Figure 1: Double ended thread bolt.

Manufacturers usually use screw of dimensions M8 $\times 80 \mathrm{~mm}$ or M8 $\times 90 \mathrm{~mm}$. For research in this paper, a screw of dimensions M8 $\times 90 \mathrm{~mm}$ was used. To fix the screw in the wooden leg, it is necessary to drill the hole of the corresponding diameter. For dining room manufacturers, it is very important to have information about the diameter of the holes on the table legs, which in combination with the selected screw, will give the optimum strength of the joint.

To test the impact of the diameter and accuracy of the drilling on the withdrawal strengths of the screws, beech planks from tangential cut with a thickness of $38 \mathrm{~mm}$ were selected. Four groups of samples (dimension $\mathrm{d} \times \mathrm{b} \times 1=33 \mathrm{~mm} \times 50 \mathrm{~mm} \times 95 \mathrm{~mm}$ ) were obtained with 20 samples whithin every group. The influence of the diameter of the drilling was examined on the samples of the first three groups by varying the diameter of the drilling. The influence of the drilling accuracy on the strength of the joint was examined on the samples of the third and fourth groups by varying the drilling accuracy class. Conditioning of samples was carried out at a temperature of $22^{\circ} \mathrm{C} \pm 2{ }^{\circ} \mathrm{C}$ and relative air humidity $40 \% \pm 3 \%$, for a period of 30 days. To test the influence of drill diameter, three groups of samples were formed, with a diameter of drilling holes of $5,0 \mathrm{~mm} ; 5,55 \mathrm{~mm}$ and $6,0 \mathrm{~mm}$ respectively. Two groups of samples were formed to study the impact of the drilling accuracy on the strength of the joint with the screw. Drills used for drilling whithin both groups had a diameter of 6,0 mm. The diameter of $6,0 \mathrm{~mm}$ was used based on the production experience in the production where tables Before installing the screws, the diameter of the drilled holes was measured on all samples. Based on the measured hole diameter, the machining accuracy for both drills have been determined.

For testing the strength and durability, dining table with dimensions height $\mathrm{x}$ vidth $\mathrm{x}$ length $=77 \mathrm{~cm} \times 80$ $\mathrm{cm} \times 120 \mathrm{~cm}$ was selected. The table top is made of veneered MDF. All other part (rails and legs) of the table are made of solid wood beech. Connection between legs and rails was done by metal corner brackets using double ended thread bolt. In the first group, table legs were drilled with a drill diameter of $D_{B}=5,0 \mathrm{~mm}$, on the second with $\mathrm{D}_{\mathrm{B}}=5,55 \mathrm{~mm}$, and on the third with $\mathrm{D}_{\mathrm{B}}=6,0 \mathrm{~mm}$. Two types of drill machines were used with different machinning accuracy: Drill 1 with the machinning accuracy class TD6 (according to DIN 68101 (2012-02), and Drill 2 . On the fourth group, legs are drilled with a drill diameter of $D_{B}=6,0 \mathrm{~mm}$, inwith the class of machinning accuracy TD15. Samples were conditioned in at temperature $24^{\circ} \mathrm{C} \pm 2{ }^{\circ} \mathrm{C}$ and relative air humidity $54 \% \pm 3 \%$, for a period of 30 days.

Withdrawal strengths of the screws, was carried out according to the international standard ISO 9087 (1998) using a universal tearing machine of Amsler, a capacity of $40000 \mathrm{~N}$. The machine is equipped with load-measuring instruments, and the test results are monitored on a computer. Before pulling out the screws, the machine was calibrated in Newtons. This value is subtracted from each gain of the maximum force required to pull the screws. The screws are pulled out 150 minutes after placing them in the samples. According to ISO 9087 (1998), pullout time was from 60 to 120 seconds, and the specific resistance of the wood to the drawing of the screws is calculated using the Equation 1:

$$
\sigma_{W}=\frac{F_{\max }}{l\left(\frac{N}{m m}\right)}
$$

Where:

W- mark for moisture content at the moment of testing;

$\mathrm{F}_{\max }-\operatorname{maximum} \operatorname{load}(\mathrm{N})$;

1-screw depth (mm).

The conical ending (the tip) of the screw has a length of $6 \mathrm{~mm}$, and smaller diameter than the outer diameter of the screw. The tip serves for positioning or guiding the screw during its installation in a previously drilled hole. The drilled hole has a cylindrical shape, so that the conical ending does not participate in holding the 
screws. Therefore, the length of the tip is taken from the length of the screw on which the threads are stretched, so that the effective depth on which the screw is placed is obtained through the Equation 2:

$$
l=L_{1}-L_{k}(m m)
$$

Where:

$\mathrm{L}_{1}$ - length of the screw with the threads $(\mathrm{mm})$;

$\mathrm{L}_{\mathrm{k}}$ - length of the conical ending $(\mathrm{mm})$.

Accordingly to it $\mathrm{L}_{1}-\mathrm{L}_{\mathrm{k}}=40 \mathrm{~mm}-6 \mathrm{~mm}=34 \mathrm{~mm}$, so the pattern for calculating the resistance of the wood to the drawing of the screws, according to Equation 1, takes the following form Equation 3:

$$
\sigma_{W}=\frac{F_{\max }}{34\left(\frac{N}{m m}\right)}
$$

\section{Durability of dining tables}

During the testing of the strength and durability of dining tables, previously tested factors such as drilling diameter and drilling accuracy were varied on the legs of the table. Since the samples are taken from the regular production, the position of the anual rings on the cross-section of the leg of the table is not controlled, so the impact of the anatomical direction on durability and stiffness was not examined.

Durability of tables, was tested according to the standards EN 12521 (2015) and EN 1730 (2012), due to the effect of horizontal forces on the board table in the transverse and longitudinal direction, and is expressed by the number cycles in the mentioned directions. The attack force line is $50 \mathrm{~mm}$ from the edge of the table, viewed in both directions (Figure 2). The testing of durability and riggidity was carried out on the testing device (producer "Hagewald \& Peschke").

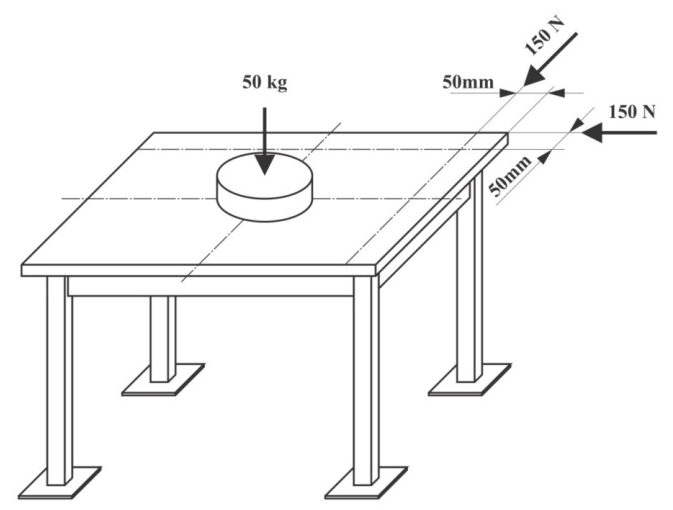

Figure 2: Setup for testing.

The testing of durability and riggidity was devided in two phases. In the first phase testing was conducted untill table reaches maximum of 10000 cycles. In the second phase, which fallowed up right afther first phase, testing is continued until table loose its rigidity, or in the case that some damages occures.

\section{RESULTS AND DISCUSSION}

Processing statistical data obtained by research implied the application of descriptive statistics, parametric and non-parametric statistical methods, correlation and regression analysis. Parametric methods involved testing the significance of the difference, using Student's T-test for independent and dependent samples, a 
single-factor analysis of the variance of repeated measurements. The basic requirement for the implementation of Student's T-test is that the samples have a normal distribution. Statistically, according to the "Central Boundary Theorem", it is assumed that in large sets (30 samples and more), the samples have a normal distribution. As there were 30 samples of samples in the examined sample assemblies, and more, the normal distribution was not statistically investigated. Non-parametric methods included testing the significance of the difference between the examined sizes, using the Kruskal-Wallis and Mann-Whitney test.

\section{Withdrawal capacities of the screws}

\section{Influence of diametar of drilled hole}

Based on the results of the statistical analisys (Table 1), the highest average value of the withdrawal capacities of the screws showed samples with drilled holes of diameter $D_{B}=5,0 \mathrm{~mm}$. This is expected result, because this group of samples had largest contact surface between the screw and the wood. Another study showed similar results. Li et al. (2011) studied the effects of the screw number and contact area. Among other things they concluded that withdrawal resistance will increse with increasment of contact surface. If we anlyze the shape of the hole (between the hole and the root of the screw), the first group of samples has overlap. Therefore, when the screw were pulled out, these overlap formed friction between the surface of the root of the screw and the wood core, which additionally had a positive effect on the withdrawal capacities. On the other hand, for samples with a diameter of a drilled hole of 5,55 $\mathrm{mm}$ and $6,0 \mathrm{~mm}$ a gap appeared between the hole and the root of the screw (Figure 3). Similar conclusion was brought out by Broker and Krause (1991). They concluded that the screw withdrawal resistance value is linearly proportional with screw diameter. Similar conculsions was obtained by Yorur et al. (2020). Regardells to type of material they have used (MDF and particle borards) they shoved that ratio between root of screws and predilled hole has significant influence on screw withdrawal strength. They also concluded that friction coefficinet has major inpact on holding strength. They didnt propose ratio between predilled hole and screw root, but from obtained results it can be cocluded that similar relation which is used in this analisys $\left(D_{B}=0,9 \cdot d 1(\mathrm{~mm})\right.$, where "d1" is the diameter of the root of the screw), is most effective.

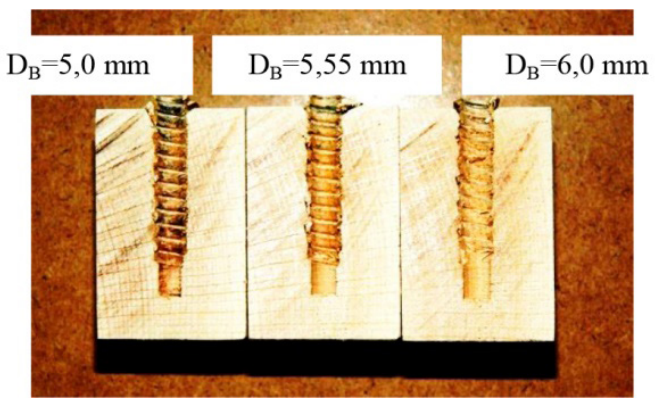

Figure 3: Crosssections of samples.

Samples where drilled holes was $5,55 \mathrm{~mm}$ showed a lower average value of the withdrawal capacities (from $306,02 \mathrm{~N} / \mathrm{mm}$ ), while the lowest average value of $300,62 \mathrm{~N} / \mathrm{mm}$ was provided by samples with diameter of drilled holes of $D_{B}=6,0 \mathrm{~mm}$. Comparinng the coefficients of variation as a measure of variability in Table 1 , it can be noticed that increase in the diameter of the drilled hole, increaseis the dissipation of the values within the sample groups.

Table 1: Value of the withdrawal capacities of the screws depending on diametar of hole.

\begin{tabular}{|c|c|c|c|c|c|c|c|}
\hline $\begin{array}{c}\text { Drill } \\
\text { dimetar } \\
(\mathrm{mm})\end{array}$ & $\begin{array}{c}\mathrm{N}^{\mathrm{o}} \\
\text { samples }\end{array}$ & $\begin{array}{c}\text { Min. } \\
(\mathrm{N} / \mathrm{mm})\end{array}$ & $\begin{array}{c}\text { Maks. } \\
(\mathrm{N} / \mathrm{mm})\end{array}$ & $\begin{array}{c}\overline{\mathrm{x}} \\
(\mathrm{N} / \mathrm{mm})\end{array}$ & $\begin{array}{c}\sigma_{\overline{\mathrm{x}}} \\
(\mathrm{N} / \mathrm{mm})\end{array}$ & $\begin{array}{c}\sigma \\
(\mathrm{N} / \mathrm{mm})\end{array}$ & $\begin{array}{c}v \\
(\%)\end{array}$ \\
\hline 5,0 & 76 & 251,50 & 418,68 & 313,79 & 3,81 & 33,21 & 10,58 \\
\hline 5,55 & 76 & 249,32 & 389,94 & 306,02 & 3,79 & 33,03 & 10,79 \\
\hline 6,0 & 76 & 239,74 & 417,50 & 300,62 & 3,92 & 34,14 & 11,36 \\
\hline
\end{tabular}


By single-factor analysis of variance of repeated measurements, the values of withdrawal capacities were compared when drilled hole was $5,0 \mathrm{~mm}, 5,55 \mathrm{~mm}$ and $6,0 \mathrm{~mm}$. Table 2 shows the results of statistical analysis. A significant influence of the diameter of the drilling was determined (Vilks lambda $=0,682 ; \mathrm{F}(2,74)=$ 17,$283 ; \mathrm{p}<0,0005$ ), with the effect size $\varepsilon^{2}=0,318$, on the basis of which it can be concluded that approximately $32 \%$ of withdrawal capacities is influenced by the diameter of the drill hole. Based on the results of the post-hoc test, the least significant difference shown in Table 2 found that there was a statistically significant difference in withdrawal capacities for all three examined groups of samples.

Table 2: The results of post-hoc test.

\begin{tabular}{|c|c|c|c|c|}
\hline \multirow{2}{*}{$\begin{array}{c}\text { (I) Hole diametar } \\
(\mathrm{mm})\end{array}$} & $\begin{array}{c}\text { (J) Drill diametar } \\
(\mathrm{mm})\end{array}$ & $\begin{array}{c}\text { Difference } \\
\text { between standard } \\
\text { deviations (I-J) } \\
(\mathrm{N} / \mathrm{mm})\end{array}$ & $\begin{array}{c}\text { Standard } \\
\text { deviation } \\
(\mathrm{N} / \mathrm{mm})\end{array}$ & p-value \\
\hline \multirow{2}{*}{5,0} & 5,55 & $7,766^{*}$ & 1,709 & 0,000 \\
\cline { 2 - 5 } & 6,0 & $13,171^{*}$ & 2,327 & 0,000 \\
\hline \multirow{2}{*}{5,55} & 5,0 & $-7,766^{*}$ & 1,709 & 0,000 \\
\cline { 2 - 5 } & 6,0 & $5,405^{*}$ & 1,998 & 0,008 \\
\hline \multirow{2}{*}{6,0} & 5,0 & $-13,171^{*}$ & 2,327 & 0,000 \\
\hline & 5,55 & $-5,405^{*}$ & 1,998 & 0,008 \\
\hline
\end{tabular}

Comparing values between groups of samples, based on a difference of 7,766 N/mm, it can be concluded that samples with a diameter of drilling a hole of $5,0 \mathrm{~mm}$ gave a higher resistance value on average by $2,5 \%$ compared to the samples with diameter of the drill hole of $5,55 \mathrm{~mm}$. Based on the difference of $13,171 \mathrm{~N} / \mathrm{mm}$, it can be concluded that the samples with a diameter of 5,0 $\mathrm{mm}$ drilling gave a higher resistance by an average of $4,4 \%$ compared to samples with a drilling diameter of the hole of $6,0 \mathrm{~mm}$. Also, based on the difference of $5,405 \mathrm{~N} / \mathrm{mm}$, it can be concluded that the samples with a diameter of $5,55 \mathrm{~mm}$ drilling diameter gave a higher resistance by an average of $1,8 \%$ compared to samples with a drilling diameter of $6,0 \mathrm{~mm}$. Based on the obtained results and their statistical annalisys, it can be concluded that as the diameter of the drilled hole increases, withdrawal capacities of the screws decreases, Figure 4. This conclusion corresponds with results presented by Li et al. (2011), but it is not in corelation with with the literatures (Eckelman 1988, Haftkhani et al. 2011). They indicated that withdrawal strength increases gradually as pilot hole increases until the pilot hole nears the root diameter of the screw.

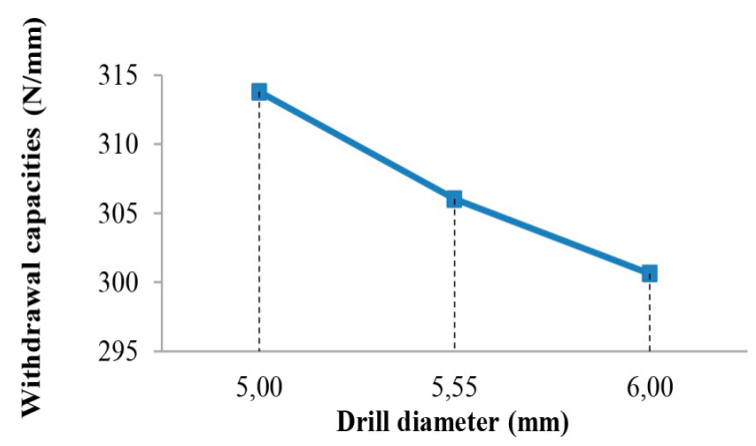

Figure 4: Influence of the diameter of the drilled hole on withdrawal capacities of the screws.

In his research Aytekin (2008) investigated withdrawal capacities of the screws from four dufferent wood species. In experiment he was usuing tree deferent types of screws smart, serrated and convencional. Average values for oak from tangential cut was between $368 \mathrm{~N} / \mathrm{mm}$ and $445 \mathrm{~N} / \mathrm{mm}$, while for fir was in a range from $200 \mathrm{~N} / \mathrm{mm}$ to $266 \mathrm{~N} / \mathrm{mm}$. Among other things he concluded, that the difference between different types of screws are not notable. There is no information about relationship between hole and the screw. If we compaire 
obtained results with presented ones, we can see that thera are some differences which can be exsplained by different wood species and different screw diameter.

In his study Dacić et al. (2017b) revealed that the withdrawal strength would be slow down while the pilot hole diameter increased. In addition, when the pilot hole diameter further increased, the withdrawal strength would be sharply reduced. With the pilot hole diameter increased from $2 \mathrm{~mm}$ to 3,5 $\mathrm{mm}$, withdrawal resistance changed for about $25 \%$. This result attributed to the decrease of screw shearing.

\section{Influence of machining acuracy on withdrawal capacities of the screws}

The higher average values of the withdrawal capacities of the screws $(300,07 \mathrm{~N} / \mathrm{mm})$ showed the samples drilled at machine 1 (Table 3). The variability expressed through the coefficient of variation was uniform for both groups of samples.

Table 3: Influence of machining acuracy on value of the withdrawal capacities of the screws.

\begin{tabular}{|c|c|c|c|c|c|c|c|}
\hline \multicolumn{8}{|c|}{ Withdrawal capacities of the screws } \\
\hline machine & $\begin{array}{c}\mathrm{N}^{\mathrm{o}} \\
\text { samples }\end{array}$ & $\begin{array}{c}\text { Min. } \\
(\mathrm{N} / \mathrm{mm})\end{array}$ & $\begin{array}{c}\text { Maks. } \\
(\mathrm{N} / \mathrm{mm})\end{array}$ & $\begin{array}{c}\overline{\mathrm{x}} \\
(\mathrm{N} / \mathrm{mm})\end{array}$ & $\begin{array}{c}\sigma_{\overline{\mathrm{x}}} \\
(\mathrm{N} / \mathrm{mm})\end{array}$ & $\begin{array}{c}\sigma \\
(\mathrm{N} / \mathrm{mm})\end{array}$ & $\begin{array}{c}v \\
(\%)\end{array}$ \\
\hline 1 (TD6) & 75 & 239,74 & 417,50 & 300,07 & 3,93 & 34,03 & 11,34 \\
\hline 2 (TD15) & 75 & 201,03 & 349,65 & 257,48 & 3,52 & 30,50 & 11,85 \\
\hline
\end{tabular}

The significance of the difference between the average values of the withdrawal capacities obtained in the two drills mentioned above was tested by the Student's T-test for the dependent samples, Figure 5. The results of the T-test have shown that there is a statistically significant difference between the samples drilled by Drill 1 and samples drilled by Drill 2, $(\mathrm{t}=14,918 ; \mathrm{df}=74 ; \mathrm{p}<0,0005)$.

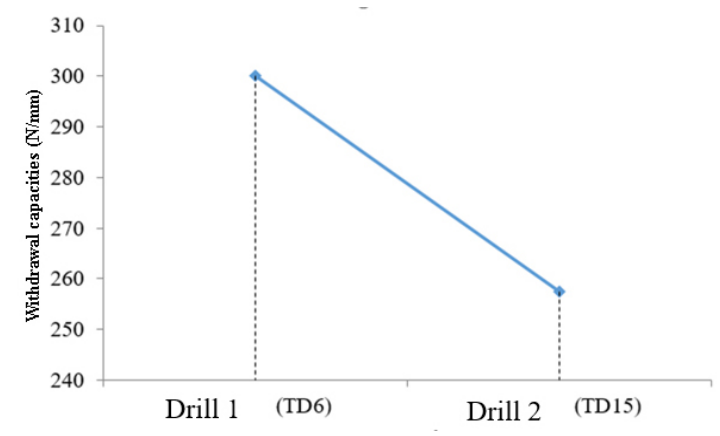

Figure 5: Average values of the withdrawal capacities.

The average value of the withdrawal capacities of the samples drilled at machine 1 is larger by an average of 16,54 . Based on the above results, note that the accuracy of drilling significantly affects the withdrawal capacities. The lower accuracy of the drilling machine causes a higher diameter of the drilling, thereby reducing the contact surface between the threads of the screw and the wood. These results coresponds with results presented by other researchers working on different types of joints Prekrat and Smardzewski (2010), Rüdiger et al. (1995), Smardzewski and Papuga (2004). All of them concluded that machinning accuracy has positive impact on joint strength. As in preveious test explanation is very much the same. Lower level of machinning accuracu will led to a smaler contact surface between the screw and the wood indicating ower values of the withdrawal capacities.

\section{Strength and durability of tables}

All samples fullfiled demands accoriding to durability test. This means that the diameter of the drilling and the accuracy of the drilling do not significantly affect the durability of the dining tables. In the statistical analysis of riggidity, the factor of the cycle number is ignored, since at all tables in both groups there are 10000 cycles. Sizes of deflection was recoreded afther 100, 500, 2500 and 10000 cycles, both in the transverse, and 
in the longitudinal direction (Table 4).

Table 4: Durabilty results.

\begin{tabular}{|c|c|c|c|c|c|c|c|c|}
\hline \multirow{3}{*}{$\begin{array}{l}\text { Durabilty } \\
\text { (cycles) }\end{array}$} & \multicolumn{6}{|c|}{ direction $(\mathrm{mm})$} & \multirow{3}{*}{$\begin{array}{c}\text { drill } \\
\text { diameter } \\
(\mathrm{mm})\end{array}$} & \multirow{3}{*}{$\begin{array}{l}\text { Machining } \\
\text { accuracy }\end{array}$} \\
\hline & \multicolumn{2}{|c|}{ I } & \multicolumn{2}{|c|}{ II } & \multicolumn{2}{|c|}{ III } & & \\
\hline & transverse & longitudinal & transverse & longitudinal & transverse & longitudinal & & \\
\hline 100 & 7 & 6 & 6 & 6 & 6 & 5 & \multirow{4}{*}{5,0} & \multirow{12}{*}{ TD 6} \\
\hline 500 & 7 & 6 & 6 & 5 & 6 & 5 & & \\
\hline 2500 & 7 & 6 & 6 & 5 & 6 & 5 & & \\
\hline 10000 & 7 & 6 & 6 & 5 & 6 & 5 & & \\
\hline 100 & 8 & 6 & 7 & 5 & 6 & 5 & \multirow{4}{*}{5,55} & \\
\hline 500 & 7 & 5 & 7 & 5 & 6 & 5 & & \\
\hline 2500 & 7 & 5 & 7 & 5 & 6 & 5 & & \\
\hline 10000 & 7 & 5 & 7 & 5 & 6 & 5 & & \\
\hline 100 & 7 & 6 & 7 & 6 & 8 & 7 & \multirow{4}{*}{6,0} & \\
\hline 500 & 7 & 6 & 8 & 7 & 7 & 6 & & \\
\hline 2500 & 7 & 6 & 7 & 6 & 7 & 6 & & \\
\hline 10000 & 7 & 6 & 7 & 6 & 7 & 6 & & \\
\hline 100 & 8 & 7 & 8 & 7 & 8 & 7 & \multirow{4}{*}{6,0} & \multirow{4}{*}{ TD15 } \\
\hline 500 & 8 & 7 & 8 & 7 & 8 & 7 & & \\
\hline 2500 & 8 & 6 & 8 & 6 & 8 & 7 & & \\
\hline 10000 & 8 & 6 & 8 & 7 & 8 & 7 & & \\
\hline
\end{tabular}

The Mann-Whitney test showed that the size of the deflection between the groups of tables of different dri-lling accuracy classes (TD6 and TD15) differed considerably in the transverse $(\mathrm{z}=-4,05 ; \mathrm{n}=12 ; \mathrm{p}$ $<0,0005)$ and the longitudinal direction $(\mathrm{z}=-2,81 ; \mathrm{n}=12 ; \mathrm{p}<0,005)$. Higher valaues of rigidity was given by a group of tables where the holes in the legs were drilled in the higher accuracy class TD6 in relation to the accuracy class TD15 in both directions.

The Kruskal Wallis test revealed a statistically significant difference in the transverse rigidity between three groups of tables with a different diameter of the hole drilling on the legs $\left(D_{B}=5,0 \mathrm{~mm}, \mathrm{n}=12 ; \mathrm{D}_{\mathrm{B}}=\right.$ $\left.5,55 \mathrm{~mm}, \mathrm{n}=12 ; \mathrm{D}_{\mathrm{B}}=6,0 \mathrm{~mm}, \mathrm{n}=12\right), \chi^{2}(2, \mathrm{n}=36)=11,95 ; \mathrm{p}<0,05$. Also, the test revealed a statistically significant difference in the longitudinal stiffness between the three groups of tables with a different diameter of the hole drill hole, $\chi^{2}(2, n=36)=20,78, p<0,05$.

The analyzed factors did not affect the durability of the tables, so the differences in the size of the defect as factor of rigidity between groups of tables can be considered negligible. Therefore, the correlation between the withdrawal capacities and testing the stiffness and durability of the dining tables can not be predicted.

\section{CONCLUSIONS}

In this study, the effect of relation of diametar of pilot hole and screw, and machinning accuracu on withdrawal strengths of the screws and durability of the dining tables were investigated. The performed investigations revealed following conclusions:

The diameter of the drilled hole significantly influences the value of the withdrawal strengths of the screws. With the increase in the diameter of the drilling, withdrawal strengths decreases;

On the basis of the obtained results, the formula for calculating the drilling diameter of the hole $\mathrm{D}_{\mathrm{B}}=0,9$ $\mathrm{d} 1(\mathrm{~mm})$, where "d1" is the diameter of the root of the screw, can be taken as a recommendation;

By controlling the ratio of the diameter of the drilled hole and the diameter of the root of the screw, it can significantly affect the strength of the joint;

Drilling accuracy significantly influenced the value of wood resistance by pulling the screws. With a fall in the drilling accuracy class, the resistance of the wood to pulling the screws decreases;

Drilling holes with machines operating in a higher class of accuracy can significantly affect the wood resistance by pulling the screws; 
By analyzing the effect of drilling diameter on rigidity of tables, a statistically significant difference was determined. As the drilling diameter increases, the rigidity of the examined dining tables decreases;

An analysis of the impact of drilling accuracy on table rigidity revealed a statistically significant difference. Drilling in a lower class of accuracy, the rigidity of the examined dining tables decreases.

Bearing in mind the results of the performed test and statistical calculations, the following conclusions were drawn. The analyzed factors did not affect the durability of the tables, so the differences in the size of the defect as stiffness measurements between groups of tables can be considered negligible. The correlation between the withdrawal strengths of the screws and testing the stiffness and durability of dining tables can not be predicted.

\section{REFERENCES}

Abdulkadir, M.; Yerlikaya, N.C.; Ozsahin, S. 2014. Evaluation and optimization of bending moment capacity of corner joints with different boring plans in cabinet. Wood Res-Slovakia 59(1): 201-216. http://www.woodresearch.sk/wr/201401/17.pdf

Akyildiz, M.H.; Malkoçoglu, A. 2001. Wood screw withdrawal resistance of some important tree species growing in eastern blacksea region (in Turkisch). Kafkas Üniversitesi Artvin Orman Fakültesi Dergisi (1): 5460. http://ofd.artvin.edu.tr/en/download/article-file/25585

Atar, M.; Ayhan, O. 2008. The effects of screw and back panels on the strength of corner joints in case furniture. Mat Des 29(2): 519-525. https://doi.org/10.1016/j.matdes.2007.01.015

Aytekin, A. 2008. Determination of Screw and Nail Withdrawal Resistance of Some Important Wood Species. Int J Mol Sci 9: 626-637. https://doi.org/10.3390/ijms9040626

Broker, F.W.; Krause, H.A. 1991. Preliminary Investigations on screwing in dynamic tests. European Journal Wood and Wood Prod 49(10): 381-384 https://link.springer.com/article/10.1007/BF02608920

Chen, M.; Lyu, J. 2018. Properties of double dowel joints constructed of Medium Density Fiberboard. Maderas-Cienc Tecnol 20(3): 369-380. https://scielo.conicyt.cl/pdf/maderas/v20n3/0718-221X-maderas-03801.pdf

Dacić, V.; Džinčić, I.; Nestorović, B. 2017a. Effect of drilling diameter on screw withdrawal resistance of wood. In Third International Scientific Conference Wood technology and product design, Ohrid, Macedonia. 155-166. http://www.fdtme.ukim.edu.mk/en/conference-2017/Proceedings-Ohrid-2017.pdf

Dacić, V.; Todorović, N.; Popović, Z.; Džinčić, I. 2017b. Screw withdrawal resistance of beech wood. In Third International Scientific Conference Wood technology and product design, Ohrid, Macedonia. 143-154. http://www.fdtme.ukim.edu.mk/en/conference-2017/Proceedings-Ohrid-2017.pdf

DIN. 2012. Grundabmaße und Toleranzfelder für Holzbe - und -verarbeitung. DIN 68101: 2012-02. https://dx.doi.org/10.31030/1857690

Eckelman, C.A. 1975. Screwholding Performance In Hardwoods and Particleboard. Forest Prod J 25(6): 30-35. 44-48.

Eckelman, C.A. 1988. Performance testing of furniture. Part I: Underlying concepts. Forest Prod J 38(3):

EN. 2015. Furniture-Strength, durability and safety - Requrements fod domestic tables. EN 12521. CENCENELEC: Brussels.

EN. 2012. Furniture. Tables. Test methods for the determination of stability, strength and durability. EN 1730. CEN-CENELEC: Brussels. 
Gašparik, M.; Barcik, Š.; Boruvka, V.; Holček, T. 2015. Impact of Thermal Modification of Spruce Wood on Screw Direct Withdrawal Load Resistance. BioResources 10(1): 1790-1802. https://bioresources. cnr.ncsu.edu/wp-content/uploads/2016/06/BioRes_10_1_1790_Gasparik_BH_Impact_Therm_Mod_Spruce_ Screw_Withdrawal_Strength_6470.pdf

Gavronski, T. 2006: Rigidity-strangth Models and Stress distribution in housed tenon joints subjected to torsion. Electronic Journal of Polish Agricultural Universities 9(4). http://www.ejpau.media.pl/volume9/ issue $4 /$ art-32.html

Haftkhani, A.R.; Ebrahimi, G.; Tajvidi, M.; Layeghi, M. 2011. Investigation on withdrawal resistance of various screws in face and edge of wood-plastic composite panel. Mate Des 32(7): 4100-4106. https://doi.org/10.1016/j.matdes.2011.02.065

ISO. 1998. Wood - Determination of nail and screw holding power under axial load application. ISO 90871998. Geneva, Switzerland. https://www.iso.org/obp/ui/\#iso:std:iso:9087:ed-1:v1:en

Kjucukov, G.; Encev, E. 1977a. The Effect of Screw Sizes on the Withdrawal Resistance in Fir Wood. Holztechnol 18(1): 26-29.

Kjucukov, G.; Encev, E. 1977b. The Effect of Screw Dimensions on the Withdrawal Resistance in Beech Wood. Holztechnol 18(3): 149-151.

Li, J.Q.; Chen, L.H.; Su, T. 2011. Study on bolt joint intensity of laminated bamboo for furniture. Journal of Fujian College of Forestry 3: 271-275. http://caod.oriprobe.com/articles/28445020/Study_on_bolt_joint_ intensity_of_laminated_bamboo_for_furniture.htm

Prekrat, S.; Smardzewski, J. 2010. Effect of glue line shape on strength of mortise and tenon joint. Drvna Ind 61(4): 223-228. https://hrcak.srce.hr/62476

Rűdiger, A.; Dusil, F.; Feigl, R.; Froelich, H.H.; Funke, H. 1995. Grundlagen des Möbel - und Innenausbau. DRW - Verlag: Stuttgart: 95p

Smardzewski, J.; Papuga, T. 2004. Stress distribution in angle joints of skeleton furniture. Electronic Journal of Polish Agricultural Universities 7(1). http://www.ejpau.media.pl/volume7/issue1/wood/art-05.html

Skakić, D.; Janićijević, S. 2000. Effect of type of joint, machining precision, and type of fit on the strength of the joints in chairs. Drvarski glasnik 9(35/36): 21-25.

Taj, M.A.; Najafi, K.; Ebrahimi, G. 2009. Withdrawal and lateral resistance of wood screw in beech, hornbeam and poplar. European Journal Wood and Wood Prod 67(2): 135-140. https://link.springer.com/article/10.1007/s00107-008-0294-9

Tankut, N. 2011. The influence of pilot hole on the moment resistance of screwed T-Type furniture joints. $S G G W$ 73: 75-84. http://yadda.icm.edu.pl/yadda/element/bwmeta1.element.agro-dbd82e15-3cb0-4079-a039a6b8213f7e3f

Yorur, H.; Birinci, E.; Gunay, M.N.; Tor, O. 2020. Effects of factors on direct screw withdrawal resistance in medium density fiberboard and particleboard. Maderas-Cienc Tecnol 22(3): 375-384. http://dx.doi.org/10.4067/S0718-221X2020005000311

Yuksel, M.; Ali, K.; Erdil, Y.Z.; Acar, M.; Kuskun, T. 2015. Effects of the panel and fastener type on bending moment capacity of 1-type joints for furniture cases. Pro Ligno 11(4): 426-431. http://www.proligno. ro/en/articles/2015/4/Yuksel_final.pdf

Yuksel, M.; Nadir, Y.; Ali, K.; Erdil, Y.Z.; Demirci, S. 2014. Effect of the panel type and panel thickness on moment resistance of screw-jointed corner joints and stiffness of four-member c abinets. Bioresources 9(4): 6340-6349. https://bioresources.cnr.ncsu.edu/wp-content/uploads/2016/06/BioRes_09_4_6340_Yuksel_Effect_Panel_Type_Panel_Thickness_Moment_Resistance_5569.pdf 